\title{
A CIDADE SE MEXE. DA BICICLETA AO CYCLE CHIC
}

\author{
MÓNICA GRACIELA ZOPPI-FONTANA*
}

\begin{abstract}
RESUMO: Este artigo explora, a partir de uma análise das materialidades discursivas, os processos de subjetivação/identificação que constituem o(s) sujeito(s) das diferentes práticas urbanas, especificamente em relação ao espaço da rua e às disputas para se afirmar nela como identidades legitimadas socialmente. Interessanos, especialmente, compreender o funcionamento dos diversos efeitos de inclusão/exclusão, segregação e silenciamento que a sobreposição de espaços e memórias múltiplos e conflitantes produz sobre os processos de construção discursiva da identidade de sujeitos socialmente discriminados em relação à cidade (em) que eles (se) significam. Focalizamos, especificamente, os processos de identificação referentes aos ciclistas e à presença da bicicleta na cidade, analisando as contradições, materialmente presentes nos enunciados, estabelecidas a partir do cruzamento das diferentes discursividades que interpretam a cidade.
\end{abstract}

Palavras-chave: mobilidade urbana, espaço público, discurso jurídico, processos de identificação

RESÚMEN: Este artículo explora, a partir del análisis de determinadas materialidades discursivas, los procesos de subjetivación/identificación que constituyen lo(s) sujeto(s) de las diferentes prácticas urbanas, específicamente con relación al espacio de la calle y a las disputas para afirmarse en ella como identidades legitimadas socialmente. Estamos interesados, especialmente, en comprender el funcionamiento de los diversos efectos de inclusión/ exclusión, segregación y silenciamiento, que produce la superposición de múltiples espacios y memorias en conflicto, sobre los procesos de construcción discursiva de la identidad de sujetos que son socialmente discriminados en relación con la ciudad (en) la cual ellos significan y se significan. Describimos, específicamente, los procesos de identificación referentes a los ciclistas y a la presencia de la bicicleta en la ciudad, analizando las contradicciones, materialmente presentes en los enunciados, establecidas a partir del cruce de las diferentes discursividades que interpretan la ciudad.

Palavras llave: movilidad urbana, espacio público, discurso jurídico, procesos de identificación

A Edna (in memoriam), que tinha orgulho de sua bicicleta.

Em fevereiro de 2011, uma notícia e um vídeo largamente veiculados na mídia televisiva e eletrônica sacudiu a opinião pública e deu lugar, por alguns dias, a um novo debate sobre a "violência no trânsito". Reproduzimos a seguir um fragmento dessa notícia:

Na sexta-feira, 25 de fevereiro, pouco depois das 19h, pelo menos 15 ciclista foram atingidos por um Golf, na rua José do Patrocínio, na área central de Porto Alegre. Oito deles foram encaminhados ao Hospital de Pronto Socorro e liberados algumas horas depois. O motorista fugiu do local. O

* (Unicamp-CNPq) 
carro foi encontrado na madrugada de sábado, abandonado em um bairro da zona leste da Capital. O motorista foi identificado [...] e alegou legítima defesa dele e do seu filho de 15 anos. (Zero Hora online, Plantão, Trânsito, 28-2-2011, 3h52min. Disponível em: http://zerohora.clicrbs.com.br/ zerohora/jsp/default.jsp?uf=1\&local=1\&section=Geral\&newsID=a3223867.xml Acesso em 4-82011)

O vídeo ${ }^{1}$ se inicia com as imagens de um passeio de bicicletas ocupando a rua no fim da tarde, do qual participam pessoas de diversas idades. A luz dourada do entardecer ilumina a cena que se desenvolve plácida, filmada de trás por um dos ciclistas. Jovens, homens e mulheres (até um cachorro na garupa da bicicleta conduzida por uma senhora) desfrutam do passeio. Porém, inesperadamente, os ciclistas voltam o rosto e, de repente, a turma é tomada pelo desespero. As imagens que chocaram os espectadores mostraram um carro preto acelerando e atropelando os ciclistas que estavam na sua frente, sem desviar e sem se deter, até passar impunemente e se perder de vista.

Casos como o relatado não são novidade, infelizmente, para a sociedade brasileira, assim como são frequentes, também, os debates sobre o tema da "violência no trânsito". Neste trabalho, tentamos deslocar o foco da discussão: em lugar de insistir sobre o discurso da violência, vamos nos interrogar sobre os sentidos da convivialidade urbana; em lugar de assumir a noção de "trânsito", vamos nos debruçar sobre os sentidos da noção de "mobilidade urbana", cuja presença dá corpo a projetos de lei recentes sobre "as condições de deslocamentos de pessoas e cargas no espaço urbano". Estaremos trabalhando, portanto, com os discursos da/sobre a cidade e nosso gesto analítico explorará essas discursividades tentando traçar, pela descrição, os caminhos que percorrem os sentidos nos seus movimentos de "delimitações, deslocamentos e transgressões" (Pêcheux, 1981).

No intuito de descrever os processos discursivos que dão corpo ao conjunto de formulações em torno da notícia do atropelamento, percorri os fios virtuais que na trama da rede web interconectam um texto a outro por meio de links ${ }^{2}$. Dois desses links se mostraram extremamente produtivos: um que comentava o movimento de ciclistas denominado Massa Crítica, com o qual se identificavam os ciclistas do passeio tragicamente interrompido; e um outro que anunciava a realização de um debate sobre Mobilidade urbana e bicicleta, promovido em São Paulo pela empresa Shimano, dedicada à comercialização de bicicletas e de equipamentos para a prática de ciclismo. Na nossa descrição seguimos estes dois fios de Ariadne, para tentar avançar no labirinto de sentidos que significam o acontecimento.

\section{CIDADE E DISCURSO}

Penso a cidade a partir dos processos de significação que constituem as imagens de cidade e de citadino/cidadão que orientam as práticas do espaço urbano. Pensar a cidade discursivamente implica, então, pensar como ela significa, quais são os sentidos produzidos

\footnotetext{
4-8-2011

${ }^{1}$ Disponível em: http://www.youtube.com/watch?v=6XL3g4vPK30\&feature=player_embedded Acesso

${ }^{2}$ Cf. Morello (2003) para uma reflexão discursiva sobre o funcionamento dos links.
} 
nela e sobre ela pelos diversos discursos que a configuram e interpretam ${ }^{3}$. O que permite refletir sobre a construção das identidades individuais e coletivas no espaço da cidade, nas suas relações de contradição constitutivas. Neste sentido, tomamos a definição de Orlandi (2001:10) para espaço urbano: "espaço material concreto funcionando como sítio de significação que requer gestos de interpretação particulares. Um espaço simbólico trabalhado na/pela história, um espaço de sujeitos e de significantes".

Assim, a cidade é compreendida como um espaço simbólico de identificação/ subjetivação, no qual os sujeitos sociais são constituídos no embate do real histórico da cidade e da sobredeterminação homogeneizante do aparelho jurídico-administrativo que a organiza com base num discurso urbanístico (Orlandi, 2001) que apaga o real da história e as contradições do político na interpretação da cidade e das relações entre sujeitos que nela se materializam.

Se, por um lado, o Estado projeta sobre o espaço urbano o esquadrinhamento de uma organização jurídica que individualiza o sujeito como "cidadão", na abstração jurídica da igualdade de direitos à cidade e deveres em relação ao Estado; por outro lado, as práticas reais do espaço urbano em condições de produção históricas concretas, divide politicamente o direito à cidade, produzindo desigualmente processos de inclusão/exclusão dos sujeitos, dando lugar à naturalização da apropriação, ocupação e uso de determinados territórios e equipamentos urbanos por determinados sujeitos e à segregação de outros sujeitos desses mesmos territórios e equipamentos. Como afirma Orlandi (2010:14):

\begin{abstract}
Não há cidadania em abstrato, sobretudo se pensarmos as atuais formas de relação do Estado (ou a sua falta de relação) com os sujeitos históricos-sociais. O que há são sítios, lugares de definição, com sua materialidade, em que se configuram processos de manifestação concreta de sentidos de cidadania que não podem ser pensados fora das condições materiais de existência desses indivíduos (sujeitos individuados) nas suas relações com a sociedade.
\end{abstract}

É importante frisar que esses sítios de significância ganham na cidade uma dimensão sensível, ou seja, a cidade produz uma representação sensível de suas formas ${ }^{4}$, afetada pelo jogo contraditório do real da história e do real simbólico. A cidade se representa na sua forma material (Orlandi, 1996), afetada pelo político e o jurídico, e dessa maneira, materializa sua corporalidade nas formulações que são produzidas nela e sobre ela.

Neste trabalho partimos da notícia de um caso de atropelamento e analisamos as formulações do texto, na sua materialidade hipertextual, e do vídeo incluído nele, como acontecimento discursivo (Pêcheux, 1983), isto é, como encontro de uma atualidade e uma memória no qual os processos de produção de sentido sobre a cidade ao mesmo tempo que retomam discursos já estabilizados, reforçando sua inscrição em determinadas regiões da memória discursiva, também deslocam essas filiações, fazendo trabalhar o equívoco, abrindo para novas interpretações.

Neste sentido, consideramos a cena descrita no início deste artigo como um flagrante da cidade (Orlandi, 2004), isto é, como: "modos seus próprios de aparição. Em gestos que

${ }^{3}$ Cf. Orlandi $(2001,2004)$ para uma apresentação dos pressupostos teóricos do trabalho de análise discursiva da cidade.

${ }^{4}$ Cf. Orlandi (2004:11). 
são e dão corpo à cidade [...] aproximando-nos do real da cidade e dos sujeitos urbanos em seu movimento, suas rupturas, sua desordem" (ibidem: 29-30). São flagrantes de um olhar e de um corpo em movimento, inscritos na própria forma material da cidade.

Como já antecipamos, para compreender este flagrante escolhemos dois eixos de análise/descrição, que estão de um ou outro modo presentes na textualização da notícia: os percursos significantes da noção de "mobilidade urbana" e os processos de identificação/ subjetivação determinados pela filiação aos novos movimentos de "cicloativismo".

\section{MOBILIDADE URBANA}

Conforme o texto publicado no blog Vá de bike, o debate realizado na Casa da Rosas, em São Paulo, reuniu como palestrantes a: "Soninha Francine, ex-vereadora e ex-subprefeita da cidade de São Paulo, e William Cruz, cicloativista". Atente-se para as duas discursividades que se fazem presentes na composição da mesa redonda:

1- o discurso político-legislativo, que traz os sentidos da organização jurídicoadministrativa dos espaços da cidade e das práticas dos sujeitos urbanos;

2- o discurso dos movimentos sociais, do "ativismo", que se apresenta como o espaço de formulação e circulação legítima de sentidos não contemplados pela organização urbana; um discurso que se auto-representa como de resistência ao poder.

Porém, quais sentidos de jurídico e de resistência estes discursos mobilizam e colocam em circulação hoje na mídia de referência?

No organograma do Ministério das Cidades existe a Secretaria Nacional de Transporte e da Mobilidade urbana - SeMob, instituída, conforme o sítio oficial desse órgão:

Com a finalidade de formular e implementar a política de mobilidade urbana ecologicamente sustentável e integrada com a política de desenvolvimento urbano, com a finalidade de proporcionar o acesso amplo e democrático ao espaço urbano, priorizando os modos de transporte coletivo e os não-motorizados, de forma segura, socialmente inclusiva e sustentável" (Disponível em: http:// www.cidades.gov.br/ Acesso em: 24 ago 2011)

Segundo o mesmo documento, três eixos estratégicos ou macro-objetivos direcionam a atuação da SeMob:

Promover a cidadania e a inclusão social por meio da universalização do acesso aos serviços públicos de transporte coletivo e do aumento da mobilidade urbana;

Promover o aperfeiçoamento institucional, regulatório e da gestão no setor; e

Coordenar ações para a integração das políticas da mobilidade e destas com as demais políticas de desenvolvimento urbano e de proteção ao meio ambiente (ibidem).

No mesmo sítio encontramos uma página dedicada à apresentação da Política Nacional de Mobilidade Urbana, que disponibiliza o projeto de lei correspondente: n.166 de 2010. No texto que precede o link ativo ao texto do projeto de lei, lemos o seguinte:

A Mobilidade Urbana Sustentável pode ser definida como o resultado de um conjunto de políticas de transporte e circulação que visa proporcionar o acesso amplo e democrático ao espaço urbano, 
através da priorização dos modos não-motorizados e coletivos de transportes, de forma efetiva, que não gere segregações espaciais, socialmente inclusiva e ecologicamente sustentável (ibidem).

Em todos os recortes citados, a questão da "mobilidade urbana" aparece associada diretamente à questão ecológica; observe-se a construção das designações: "mobilidade urbana ecologicamente sustentável"; "A Mobilidade Urbana Sustentável". Por efeito de pré-construído (Pêcheux, 1975), a formulação dessas designações apresenta como evidente, como sempre-já-lá, naturalizando-a, a relação entre mobilidade urbana e sustentabilidade. Ou dito de outro modo, os sentidos de urbanidade e de sustentabilidade se sobrepõem neste discurso, levando a interpretar o espaço urbano pelo viés do meio ambiente. Do ponto de vista discursivo, esta sobreposição contraditória de sentidos formulados como sinônimos coloca em relação de continuidade: um discurso pela inclusão social/não segregação espacial e um discurso pela sustentabilidade/preservação do meio ambiente. Com efeito, observe-se que no recorte acima o sintagma nominalizado "acesso amplo e democrático ao espaço urbano" é reformulado como "não gere segregações espaciais, socialmente inclusiva e ecologicamente sustentável". Desta maneira, as políticas de mobilidade urbana são definidas como um conjunto de políticas "democráticas, de inclusão", que visam "mudar radicalmente" (ibidem) a atuação do Governo Federal, "centrada no desenvolvimento sustentável das cidades".

Como veremos adiante, é esta particular inflexão discursiva a que significa hoje a presença da bicicleta na cidade: adotar a bicicleta como meio de transporte é significado como uma "prática de cidadania ecologicamente consciente". Usar a bicicleta seria, desse modo, "tomar uma posição" a favor do meio ambiente e, ao mesmo tempo, "assumir uma posição democrática", pelo deslizamento metonímico que leva do meio ambiente à cidade e desta à democracia. Assim, constrói-se uma nova evidência: "a bicicleta é democrática".

Podemos, então, perguntar: qual bicicleta? democrática como? inclusiva para quem?

Para responder estas interrogações, exploramos no corpus os textos legislativos sobre mobilidade urbana que precedem o atual (n. 166/2010). A primeira observação relevante que pode ser feita no material é, justamente, a ausência da designação "mobilidade urbana" e de sua definição na legislação mais antiga sobre o assunto. Com efeito, o projeto de lei $n$. 166/2010 refere-se explicitamente a uma iniciativa anterior, que vem a ser substituída: o projeto n. 694 de 1995. Compare-se o caput de cada projeto:

\footnotetext{
Projeto de lei da Câmara, n. 166/2010 (n.694/1995, na Casa de origem, do Deputado Alberto Godman).

Institui as diretrizes da Política Nacional de Mobilidade Urbana; revoga dispositivos anteriores [...] e dá outras providências.
}

\section{Projeto de lei da Câmara, n. 694/1995}

Institui as diretrizes Nacionais do Transporte Coletivo Urbano e dá outras providências.

Por efeito metafórico (Pêcheux, 1969) a denominação mobilidade urbana substitui transporte coletivo urbano, alargando sua definição de modo a incluir todo tipo de deslocamento de pessoas e cargas, seja coletivo ou individual, público ou privado, motorizado ou não-motorizado. Esta abrangência maior permite incluir neste projeto de lei menções explícitas a "ciclovias" e "transporte individual não-motorizado". Continuando 
a leitura em paralelo de ambos os projetos descobrimos outras substituições que, em seu conjunto, permitem compreender o processo discursivo que produz esses deslocamentos. Vejamos:

\section{Projeto 166/2010}

Art.2. A Política Nacional de Mobilidade Urbana tem por objetivo contribuir para o acesso universal à cidade, o fomento e a concretização das condições que contribuam para a efetivação dos princípios, objetivos e diretrizes da política para desenvolvimento urbano, por meio do planejamento e da gestão democrática do Sistema Nacional de Mobilidade Urbana.

Art. 7 - A Política Nacional de Mobilidade Urbana possui os seguintes objetivos:

I- reduzir as desigualdades e promover a inclusão;

II- promover o acesso aos serviços básicos e equipamentos sociais;

III- proporcionar melhorias nas condições urbanas da população no que se refere à acessibilidade e à mobilidade;

$I V$ - promover o desenvolvimento sustentável com a mitigação dos custos ambientais $e$ socioeconômicos com os deslocamentos de pessoas e cargas na cidade;

V- consolidar a gestão democrática como instrumento e garantia da construção continua do aprimoramento da mobilidade urbana.

Art. 18 São atribuições dos Municípios [...]

II- prestar direta, indiretamente ou por gestão associada, os serviços de transporte público coletivo urbano, que tem caráter essencial.

\section{Projeto 694/1995}

Considerando [menção a diversos artigos da Constituição Nacional]

A presente proposição estabelece o balizamento requerido para que o setor de transporte coletivo urbano consiga promover o desejado salto qualitativo em seu funcionamento, que é vital para o desenvolvimento socioeconômico do Brasil, um país que já conta com $2 / 3$ da sua população vivendo em cidades, várias delas com proporções metropolitanas.

Art.2 Esta lei dispõe sobre as diretrizes nacionais do transporte coletivo urbano, determina a forma de atuação da União nesse setor e estipula as condições do repasse de apoio federal a Municípios e Estados.

Art. 6. Os serviços de transporte coletivo, de quaisquer modalidades, são considerados serviços públicos essenciais.

Parágrafo único. Os serviços podem ser prestados diretamente pelo Poder Público, ou delegados por este a entes estatais ou privados, mediante contrato de concessão ou permissão. (o destaque em itálico é nosso)

No projeto 694/1995 só é considerado o desenvolvimento socioeconômico do país, sem nenhuma menção à sustentabilidade. Compare-se o art. 7-IV do projeto 166/2010 com o Considerando do projeto 694/1995:

Projeto 166/2010: promover o desenvolvimento sustentável com a mitigação dos custos ambientais e socioeconômicos

Projeto 694/1995: desejado salto qualitativo em seu funcionamento, que é vital para o desenvolvimento socioeconômico do Brasil, um país que já conta com 2/3 da sua população vivendo em cidades,

Perceba-se que no projeto atual o "desenvolvimento sustentável" significa, por efeito de pré-construído, como um fim em si mesmo, cuja necessidade se impõe sem precisar de justificativas. Por sua parte, o aspecto socioeconômico (apresentado como prioridade 
política no projeto de 1995) torna-se um custo a ser reduzido, sendo a responsabilidade dessa redução uma questão de cidadania, portanto compartilhada por "todos" e não somente uma obrigação do Estado. Este mesmo processo de diluição e apagamento da responsabilidade do Estado no que se refere ao setor de transporte público coletivo urbano pode também ser observado ao contrapor o art. 18 inciso II do projeto 166/2010 com o art. 6 do projeto 694/1995.

Projeto 166/2010: prestar direta, indiretamente ou por gestão associada, os serviços de transporte público coletivo urbano, que tem caráter essencial.

Projeto 694/1995: Os serviços de transporte coletivo, de quaisquer modalidades, são considerados serviços públicos essenciais.

É importante destacar o deslocamento da relação de determinação do adjetivo "público" em relação à designação do serviço de transporte coletivo: no projeto de 1995 se afirma explicitamente que o transporte coletivo é um serviço público essencial, em quaisquer de suas modalidades, ou seja, é um serviço a ser garantido pelo Estado; enquanto que no projeto de 2010, é a prestação direta, indireta ou por gestão associada do transporte coletivo urbano, que tem caráter essencial; não se afirma, como no projeto precedente, que seja um serviço público essencial. O deslocamento em termos sintáticos é sutil, porém, é notório do ponto de vista discursivo, porque ele nos dá indícios do processo discursivo que distancia um projeto de lei do outro: trata-se da filiação dos enunciados do projeto atual a um discurso neoliberal no qual ao mesmo tempo que se afirma a universalidade dos direitos de cidadania, se isenta o Estado das suas responsabilidades em relação a garantir as condições de satisfação desses mesmos direitos à população.

É nesta encruzilhada discursiva em que o sujeito é interpelado ao mesmo tempo como cidadão "responsável" em relação ao Estado e ao Planeta que os novos discursos em torno ao uso da bicicleta nas grandes cidades vão se significar.

\section{A BICICLETA É ANÁRQUICO-REVOLUCIONÁRIA}

Como vimos, o incentivo ao uso da bicicleta ocorre na legislação ao mesmo tempo em que um discurso sobre a diminuição do impacto ambiental e do custo econômico provocado pelo transporte coletivo urbano ganha força na configuração discursiva que sobredetermina as práticas jurídico-administrativas do Estado e os processos de interpelação que constituem os sujeitos sociais em cidadãos "responsáveis" pela cidade. Efeitos dessa mesma configuração discursiva os encontramos em blogs, comunidades e sites da internet, nos quais os usuários de bicicleta no espaço urbano se reúnem para trocar informações e experiências e para promover o uso da bicicleta por parcelas mais significativas da população. Trata-se do "cicloativismo" virtual que organiza através da rede manifestações e intervenções presenciais no espaço das cidades brasileiras.

No caso da notícia e vídeo sobre o atropelamento de vários ciclistas em Porto Alegre, cuja menção deu início a este artigo, os participantes do passeio em bicicleta se identificavam com o movimento internacional "Massa crítica". Voltemos ao texto da notícia: 
O grupo integra o movimento Massa Crítica, que se reúne toda última sexta-feira do mês para pedalar. Segundo a estudante Lenise Ghiorzi Correa, 21 anos, que participava do projeto pela primeira vez, o grupo havia saído do Largo Zumbi dos Palmares e seguia caminho pela José do Patrocínio, bloqueando a via [...]

O grupo Massa Crítica defende a bicicleta como meio de transporte mais democrático e sustentável, em contraponto ao uso de carros, motos e ônibus. (In: "Grupo de ciclistas é atropelado na Cidade Baixa, em Porto Alegre". Zero Hora online- Trânsito, 25-2-2011. Disponível em: http:// $\mathrm{z}$ e $\mathrm{r}$ o $\mathrm{h}$ o $\mathrm{r}$ a default.jsp?uf=1\&local=1\&section=Geral\&newsID=a3221536.xml\&dsadsad Acesso em 24 jul 2011)

Conforme os próprios participantes, o Massa Crítica é um movimento social contestatário da organização de mobilidade urbana atual nas grandes metrópoles. Teve origem na cidade de São Francisco - EUA e atualmente se espalha por diversos países e cidades do planeta, realizando um passeio coletivo toda última sexta-feira de cada mês. Caracteriza-se por não possuir uma estrutura fixa e hierárquica, dependendo para sua realização do poder de convocação das redes sociais virtuais. Trata-se de uma nova forma de cyber-ativismo, cujo espaço de ação se encontra principalmente (se não exclusivamente) nas grandes cidades/metrópoles do mundo e em algumas capitais do Brasil.

O nome do movimento se origina numa ação constitutiva da prática do grupo, o "corking", que consiste em bloquear ou fechar a rua de circulação e as travessas, impedindo a passagem de carros e pedestres, para que o fluxo de ciclistas participando do passeio possa passar em massa e sem interrupções. Pelo fato de não estar constituído como uma ONG ou como qualquer outra organização civil militante, o movimento Massa Crítica não solicita autorização para a realização dos passeios, nem informa previamente às autoridades do percurso de seu trajeto, o que somado à prática do "corking", ocasiona não poucos distúrbios nas ruas e confrontos com motoristas e pedestres 5 .

No entanto, para seus participantes, o passeio coletivo e, inclusive, a prática de "corking", acrescida da entrega de panfletos e flores, são significados como uma manifestação festiva que convida à sociabilidade urbana: um convite à "fluidez da vida".

\begin{abstract}
Com uma capacidade de mobilização imensurável, a Bicicletada de São Paulo reúne todos os meses centenas de pessoas na Praça do Ciclista, a última aconteceu sexta passada, dia 29/07. O movimento gera muita polêmica, entre outros motivos, por não ter líderes, organizador nem nenhum tipo de representante.

Pra quem reclamar? Elogiar? Sugerir rotas e mudanças? A melhor (e única) maneira de propor qualquer ideia na Bicicletada é participando dela. Só quem está lá, na massa, pedalando e sentido a energia consegue entender perfeitamente o potencial anárquico-revolucionário que ela tem. (In: "Pedalando pela fluidez da vida", de Aline Morães. Blog Vá de bike. Disponível em: http:// vadebike.org Acesso em 18 jul 2011)
\end{abstract}

A bicicleta é, assim, significada como ícone de um novo movimento contra a ordem instituída, projetando sobre os participantes uma aura de rebeldia: o ciclista disputa o espaço urbano com os carros, símbolos do capitalismo individualista e predatório. A bicicleta, ao contrário, convocaria ao laço social, à indistinção de classes, à convivência pacífica, à preservação do meio ambiente.

${ }^{5}$ Cf. a descrição do movimento amplamente documentada em diversas fontes midiáticas e acadêmicas disponível em: http://en.wikipedia.org/wiki/Critical_Mass Acesso em 8 jul 2011. 
Pedalar bem vestido é uma das formas do cicloativismo. É uma negação viva, presencial e a prova de contestação da crença popular de que o ciclista sempre chega a destino sujo, suado e cheirando mal. Faz com que as pessoas entendam que ciclista não precisa ser sempre um adolescente sem camisa, um homem com roupa de atleta ou alguém que pedala por falta de dinheiro para a condução. Bicicleta é para todos. Não é coisa de esportista, de desocupado, de pobre, é coisa de gente. Gente que pode ser esportista ou preguiçosa, desocupada ou trabalhadora, pobre ou rica. A bicicleta é democrática e inclusiva. (In: "A importância do Cycle Chic". Blog Vá de bike. Disponível em: http://vadebike.org Acesso em 28 jul 2011. Destaque no original).

Assim, a bicicleta surge como a nova utopia da pós-modernidade, “democrática, sustentável e inclusiva". Convenientemente significada pelos discursos que constituem hoje a Formação Ideológica capitalista dominante (Orlandi, 2009): os discursos (formações discursivas) da mundialização, da preservação do meio ambiente, da democracia como valor universal, da inclusão e, acrescentamos, da solidariedade 6 .

\footnotetext{
E mesmo sem existir uma liderança formal, é impossível naõ notar uma organização coletiva, fluída, natural e orgânica. Presenciei dezenas de pessoas que participavam pela $1^{\mathrm{a}}$. vez da Massa Crítica fazendo "corking", distribuindo flores e sorrisos a motoristas e pedestres. MÁGICO! Taí uma das belezas do movimento: transbordar voluntariamente bom humor, cores e alegria - mesmo nos momentos mais críticos. (In: "Pedalando pela fluidez da vida", de Aline Morães. Blog Vá de bike. Disponível em: http://vadebike.org Acesso em 18 jul 2011)
}

Mas será? Por que "pedalar bem vestido" é uma forma de ativismo? Por que os mesmos autores que escrevem seus textos e comentários nos blogs que militam abertamente a favor da "bicicleta para todos" incluem com menções de admiração não dissimulada links, citações e fotos do movimento CYCLE CHIC? Que sentidos significam esta militância? Quais ela silencia, mesmo "tomando posição" explicitamente pela "inclusão democrática"?

\section{O CYCLE CHIC E "A CIDADE DAS BICICLETAS"}

Detenhamo-nos um momento em uma nova cena, um novo flagrante da cidade, tal como aparece narrado no blog VÁ DE BIKE, por seu autor, William Cruz, auto-definido como "cicloativista".

Chegando pedalando e bem vestido a um restaurante para almoçar, o maître logo me sugeriu colocar a bicicleta dentro do estabelecimento. [...]

O maître me acompanhou até a mesa perguntando:

- O senhor já morou na Europa?

- Não. Por quê?

- É que lá é que o pessoal anda de bicicleta assim, né?

- Bom, então transformemos aqui em uma Europa! - respondi, sorrindo. - Vamos melhorando nossa cidade e um dia chegaremos lá.

O maitre saiu sorrindo, mas pensativo. E eu sentei na mesa lembrando do texto do Denis Russo Burgierman, "não somos dinamarqueses". Não somos como os europeus, mas podemos ser (nos pontos que importam, claro). E essa mudança depende de todos nós. (In: "A importância do Cycle Chic". Blog Vá de bike. Disponível em: http://vadebike.org Acesso em 28 jul 2011).

\footnotetext{
${ }^{6}$ Cf. Orlandi (2009).
} 
Seguindo a teia de links proposta pelo texto no seu item "Saiba mais", encontramos referências a:

Cycle Chic - artigo do Vá de Bike explicando o assunto

Copenhagen Cycle Chic - o site que inspirou o mundo

Curitiba Cycle Chic - site nacional muito bem produzido

Gata de Rodas e Hoje vou assim de bike - sites das estilosas Verônica Mambrini e Joana Rocha Casamento de bicicleta - Fotos, vídeos e relatos do meu casamento cycle chic

Textos relacionados:

Mulheres e Bicicletas

"Copenhagenizando" o Brasil

Rio de Janeiro Cycle Chic, com Mikael Colville-Andersen

Cycle Chic

"Copenhagenize" no Rio e São Paulo, em julho

O leitor que me acompanhar nesse passeio virtual pelos diversos sites e páginas citados logo se encontrará submerso em um mundo de glamour e de estilo.

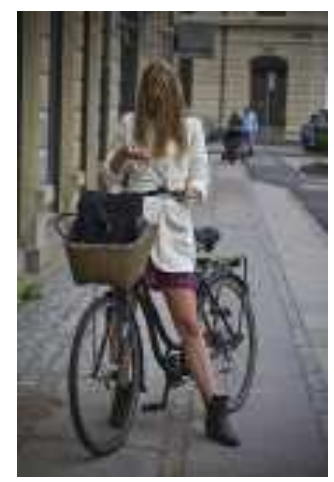

In: http://www.copenhagencyclechic.com/ Acesso 31 ago 2011

Galerias de fotos se sucedem identificadas apenas com o nome da cidade onde os (as) ciclistas chiques foram fotografados; o próprio logo identificador da cidade transpira design:
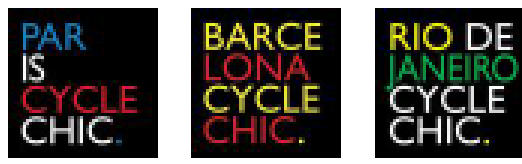

O Cycle Chic - instituído, aliás, como marca registrada ou 'trade mark' - se apresenta como um movimento criado pelo fotógrafo e cineasta dinamarquês Mikael ColvilleAndersen (considerado pelos "cicloativistas" como o "embaixador dinamarquês para assuntos de bicicleta"), que consiste em fotografar pessoas que usam a bicicleta como meio de transporte; porém, a seleção de pessoas a serem flagradas pela câmara se concentra exclusivamente naquelas que trajam "roupas sociais ou esporte fino", limpas, "estilosas", 
na moda, exalando "glamour". Observe a definição proposta pelo autor do blog Vá de bike,

Cycle Chic é a cultura de pedalar com roupas "fashion", com estilo ao se vestir. Mas, na verdade, é ainda mais abrangente: cycle chic é usar para pedalar a mesma roupa que você pretende usar no seu destino, mostrando que não é preciso se fantasiar de atleta para pedalar. ("Cycle Chic". In: Blog Vá de bike. Disponível em: http://vadebike.org/2009/02/cycle-chic/).

Mas se as mesmas roupas que serão usadas no destino não forem "fashion”? Ainda somos "cycle chic"? Acredito que o leitor deve, como eu, lembrar das múltiplas cenas de trabalhadores pedalando de madrugada na beira da estrada para chegar a seu destino, usando desde que "se entendem por gente" a bicicleta como meio de transporte. E de tantos outros que adaptaram suas bicicletas para fazer delas seu instrumento de trabalho: carregadores de galões de água, afiadores de faca, etc. De homens, mulheres e crianças do Brasil que jamais imaginaram "se fantasiar de atleta" para sair com sua bicicleta, tão familiar que ela já é nas suas vidas, tão inscrita nas suas práticas cotidianas. Milhares de pessoas, dispersas em diversas cidades brasileiras, inclusive nas metrópoles, que usam diariamente a bicicleta para se trasladar, para transportar seus familiares acomodados na garupa ou se equilibrando no quadro ou no guidão, que pedalam juntas para ir ao mercado, ao bar, à escola, a praça, a namorar. Pessoas que não precisam investir sua bicicleta de "valor agregado" (sustentável, cycle chic, democrática e inclusiva, anárquico-revolucionária) para que ela signifique no espaço urbano. Simples pessoas que usam a bicicleta, todos os dias, vestidas com suas roupas habituais, sem alarde.

Mas onde se encontram as referências a este Brasil de bicicleta no discurso do cicloativismo sustentável e democrático? Quando e como a designação "a cidade das bicicletas" passou a ser sinônimo de Copenhagen? O que silencia o discurso em prol da "copenhaguenização" do Brasil?

\section{“NÃO SOMOS DINAMARQUESES”, MESMO!}

Para quem anda pelo Brasil afora, a designação "cidade das bicicletas" está longe de referir a Copenhagen. Até não faz muito tempo, Cáceres - MT era considerada "a cidade das bicicletas", tendo sido objeto de matérias jornalísticas em programas da Rede Globo. Por outro lado, é por meio dessa designação que a cidade se auto-denomina nos materiais de divulgação turística e por meio de placas instaladas na principal avenida de acesso. Fora a disputa pitoresca pelo título de "Capital das bicicletas" estabelecida por cidades como Cáceres - MT, Joinville - SC, Indaiatuba - SP, entre outras, na mídia de referência, o que nos interessa destacar aqui são os processos discursivos que não só significam a cidade e a prática do ciclismo, como possibilitam os processos de identificação dos sujeitos em relação à circulação no espaço urbano.

Trazemos aqui, especificamente, a análise desenvolvida por Edna André Soares Melo (2007) sobre a presença da bicicleta na cidade de Cáceres-MT:

O ciclista de Cáceres, que se autodenomina 'bicicleteiro', conduz sua bicicleta, cotidianamente, pelas ruas movimentadas da cidade, concorrendo com carros, motos e pedestres na ida e vinda do 
trabalho, das agências bancárias, da escola, etc., sem observar as normas de conduta para os usuários do tráfego urbano. Por este motivo, Cáceres é conhecida como a cidade das bicicletas. A cidade onde a bicicleta é um meio de transporte que tem a preferência no trânsito, indistintamente, embora outros condutores não vejam isso de forma passiva. Há uma tensão entre a posição-sujeito ciclista com outros condutores que estão sujeitos (assujeitados) ao cumprimento da legislação de trânsito em vigor. p. 41[...]

O discurso da cidade, assim como a materialidade da própria cidade, seriam constituídos [segundo Orlandi, 2001] de falhas, de possíveis, de sentidos ainda irrealizados que sustentam, na falha e na incompletude, a possibilidade de novos sentidos. O espaço da falha, da "incompreensão", é dado aqui pela transgressão do ciclista por estar fora da norma, A falha, nesta materialidade, é vista como excesso de uma outra ordem, produzida pelas práticas cotidianas, nas relações interpessoais de condutores de veículos no espaço público da cidade.p.47 (Soares Melo, 2007)

Do trabalho de Soares Melo nos interessa apontar a descrição dos processos de identificação/interpelação do sujeito que permitem significar o conflito constitutivo entre os diversos usuários das vias da cidade. À organização jurídico-administrativa projetada sobre o espaço público se sobrepõe a ordem transgressora de práticas cotidianas que tecem uma trama complexa de relações sociais entre os sujeitos urbanos, estabelecendo uma verticalização do "direito à circulação". Em "a cidade das bicicletas" o ciclista se encontra "na posição vertical hierárquica das relações interpessoais entre os usuários das vias públicas da cidade, acionando uma memória discursiva de um dizer que "autoriza" a transgredir as leis de trânsito, por meio de práticas cotidianas aqui denominadas [de acordo com Lagazzi, 1988] de juridismo" (ibidem: 48).

As análises de Soares Melo permitem observar quão diferentes são os sentidos produzidos por e para a prática de andar em bicicleta, quando referidos a práticas concretas e historicamente determinadas e descritos na sua materialidade significante, fora da sobredeterminação imposta pelo discurso do urbanístico e do militantismo solidário ${ }^{7}$.

A afirmação "a bicicleta é para todos", destacada em negrito pelo cicloativista no seu blog, produz a universalização de um simulacro de inclusão e igualdade que, ao mesmo tempo que impõe uma organização urbanística autodeclarada democrática e inclusiva, silencia, invisibilizando perversamente sua existência, práticas reais porém diferentes de uso da bicicleta nas vias das cidades brasileiras.

No meu trabalho sobre os processos discursivos que constituem os sentidos e os sujeitos urbanos, tenho já me debruçado sobre este processo de simulação perversa de um TODOS NÓS que não somente incluiria a totalidade dos sujeitos sociais mas que funcionaria na modalidade necessária dos enunciados universais conceptual-científicos. Assim, analisei o funcionamento dos enunciados: "cuidado com estranhos" (Zoppi Fontana, 1999), "espaço público, de todos e de ninguém" (Zoppi Fontana, 2003); e a metáfora da cidade como "nossa casa, nosso jardim" (Zoppi Fontana, 2004), em cuja base encontramos a representação imaginária do "cidadão comum". No discurso do cicloativismo e da mobilidade urbana encontramos funcionamentos semelhantes, o que nos leva a retomar aqui os aspectos principais daquelas análises.

Nosso intuito é apontar uma convergência de funcionamentos que sinalizam a regularidade de um processo discursivo universalizante, que perpassa diversas instâncias

${ }^{7}$ Mariani (2001) analisa o funcionamento do discurso da solidariedade nas atuais condições de desenvolvimento do capitalismo. 
enunciativas, atravessa instituições diferentes, articula campos discursivos distintos, constituindo, assim, de maneira imbricada, elementos de saber que se impõem na sociedade produzindo consenso, o "senso comum" de um "cidadão comum" espectral.

Para melhor interpretarmos o funcionamento deste processo de universalização, vamos retomar aqui o efeito da continuidade individual/universal que Pêcheux (1975), retomando Fuchs, denominou mito continuísta empírico-subjetivista, e que definiu como o efeito de sentido “que pretende que, a partir do sujeito concreto individual 'em situação' (ligado a seus preceitos e a suas noções), se efetue um apagamento progressivo da situação por uma via que leva diretamente ao sujeito universal, situado em toda parte e em lugar nenhum, e que pensa por meio de conceitos" (op.cit., p.127) ${ }^{8}$.

Os funcionamentos discursivos trabalhados por Pêcheux através da figura do mito se referem principalmente ao efeito de apagamento da descontinuidade epistemológica entre conhecimento científico e desconhecimento ideológico. O autor descreve esse mito através de uma tabela na qual aparecem representadas as diferentes "cenas do conhecimento", começando pela relação imediata do eu (sujeito singular) com o concreto (objetos sensíveis) em uma situação discreta (vejo/aqui/agora), para passar por diversos movimentos de abstração que permitem na segunda cena uma discrepância suturada pela identificação intersubjetiva (eu/tu; aqui/agora/passado/em outro lugar; vejo/disseste); na terceira cena subsumir as tomadas individuais em um espaço de apagamento da individualidade que permite a generalização do senso comum (disseram-me <eles/x>/passado/em outro lugar); para culminar na última cena no apagamento de toda subjetividade, produzindo a sobreposição de objeto e sujeito de conhecimento no regime da indeterminação universal (qualquer um/sempre/em todo lugar) enquanto garantia de conhecimento verdadeiro. Ainda interpretando o mito, Pêcheux (1975) afirma que "o continuísmo subjacente à oposição situação/propriedade se apoia sobre o processo de identificação ("se eu estivesse onde tu (você)/ele/x se encontra, eu veria e pensaria o que tu(você)/ele/x vê e pensa")" e acrescenta que "o imaginário da identificação mascara radicalmente qualquer descontinuidade epistemológica" (op.cit.,p.128).

Esses mesmos processos de identificação imaginária permitem a sobreposição/deslize metafórico do NÓS situado em recortes concretos de espaço/tempo (como na afirmação "não somos europeus mas podemos ser" na narrativa postada no blog), para o TODOS universal (do 'cidadão comum', como na afirmação "A bicicleta é para todos", "é coisa de gente"). Desta maneira, apaga-se a descontinuidade real existente entre as diferentes posições-sujeito a partir das quais se produz sentido para o espaço urbano. Em relação especificamente aos estudos urbanos e aos discursos que interpretam a cidade, esta continuidade individual-universal apaga os efeitos da contradição no funcionamento da cidade e desconhece a desigualdade das relações no espaço urbano e, especificamente, nas vias de circulação.

Desta maneira, se produz um efeito de mascaramento/simulação da descontinuidade epistemológica (relação dos sujeitos urbanos com o que lhes é dado a conhecer -d/na cidade-) e principalmente política (relação dos indivíduos com a divisão desigual do "direito à cidade" e seus efeitos contraditórios nos processos de identificação/interpelação que os

\footnotetext{
${ }^{8}$ No que segue, retomamos a reflexão desenvolvida em Zoppi-Fontana (2003, 2004).
} 
constituem em sujeitos urbanos, através de um trabalho simbólico de inclusão/ reconhecimento nos espaços da cidade). Assim, silencia-se a dimensão política dos regimes de uso, ocupação e circulação do/no espaço urbano, sobreinterpretada pelos sentidos de sustentabilidade, democracia, inclusão, solidariedade e mobilidade urbana, que produzem efeitos de universalização e indeterminação semântica na construção do sujeito do discurso. Através deste processo de universalização, definem-se, por um lado, os cidadãos (identificados ainda como TODOS NÓS na continuidade individual-universal que funda tanto o discurso jurídico quanto o discurso urbanístico) e recorta-se, ao mesmo tempo, como resíduo dessa operação, um lugar de exclusão ao qual são relegados aqueles que ficam fora do NÓS, aqueles que são não só silenciados mas condenados à invisibilidade e à inexistência virtual e midiática.

Essa rachadura, que sinaliza o engodo constitutivo do mito continuísta empírico subjetivista, aparece presente mas dissimulada no funcionamento dos enunciados que definem a bicicleta como sendo "para todos", como "coisa de gente".

Este deslizamento metonímico, que leva do eu ao nós ("não somos europeus, mas podemos ser") e finalmente ao todos ("a mudança depende de todos nós", "coisa de gente"), faz invisíveis as descontinuidades reais que dividem contraditoriamente o urbano, enquanto ordem real da cidade. Esses processos de sobreinterpretação universalizante e dissimulação da contradição constituem uma das condições de funcionamento e de realização da ideologia. Pêcheux (1975) compara esses processos com o que os lógicos de PortRoyal chamavam a universalidade moral que permite que se diga "os franceses são valentes; os italianos são desconfiados; os alemães são grandes; os orientais são voluptuosos, porque basta que isso seja verdadeiro para a maioria"(op.cit., p.182, nota 20). Podemos acrescentar à lista: "a bicicleta é coisa de gente", "não somos europeus mas podemos ser; essa mudança depende de todos nós", e tantas outras afirmações cuja "universalidade moral" distribui "igualitariamente" identidades e direitos, a partir do gesto de interpretação de uma posiçãosujeito, que sem sequer ser maioria, conta com livre acesso à mídia e às instâncias políticoadministrativas. Vale a pena lembrar, ainda, que:

\footnotetext{
A dominação da ideologia política introduz assim, por meio de seu universalismo, uma barreira política invisível, que se entrelaça sutilmente com as fronteiras econômicas visíveis engendradas pela exploração capitalista. [...] Esta estratégia da diferença sob a unidade formal culmina no discurso do Direito, que constitui assim a nova língua de madeira da época moderna, na medida em que ela representa no interior da língua, a maneira política de negar a política.(Pêcheux, 1982a, p.10-11; grifos do autor; sublinhado nosso).
}

Fora do discurso da sustentabilidade, da "tomada de posição consciente e responsável" pelo meio ambiente, do discurso da solidariedade que leva ao militantismo alegre e bemhumorado, do discurso da inclusão e das igualdades democráticas, as práticas reais de milhares de brasileiros que fazem da bicicleta seu meio de transporte ficam silenciadas, invisibilizadas, relegadas à crença popular "de que o ciclista sempre chega ao destino sujo, suado e cheirando mal".

Movimento perverso dos discursos dominantes, que na configuração atual que alia capitalismo globalizado, democracia universalizante, inclusão solidária e responsabilidade sócio-ambiental, projetam suas evidências de "desenvolvimento sustentável" sobre os 
processos de identificação que constituem os sujeitos nas suas reais condições de existência material. O que leva a responsabilizar os próprios sujeitos sociais, constituídos como “cidadãos responsáveis", pela falência do Estado na organização dos conflitos urbanos, pelo abandono de seu compromisso constitucional em oferecer serviços públicos de transporte coletivo, pela segregação territorial na qual são jogados milhares de moradores varridos das regiões "nobres" da cidade pela especulação imobiliária desenfreada.

Como subjetivar-se na diferença em relação ao discurso da mobilidade urbana sustentável, tal como vimos na análise de Soares Melo sobre os ciclistas da cidade de Cáceres-MT? Como "andar de bicicleta e ser feliz" na "fluidez da vida", quando os discursos mundializados do cicloativismo democrático defendem o figurino glamouroso do Cycle Chic? Que espaços de subjetivação restam para o ciclista que roda na contramão deste fluxo discursivo importado? Como não sucumbir ao peso da "culpa" pela inadequação do próprio corpo ao corpo social e urbano higienizado, que estes discursos nos apresentam?

\footnotetext{
Por diversas vezes tentei sair de cycle chic o o problema é que transpiro d+.

Quando é uma reta até consigo não transpirar porem numa subida não importa a velocidade que vou sempre transpiro!

Mas parabenizo que consegue!!!

(Comentário incluído por um leitor em referência ao post "Cycle chic". In: Blog Vá de bike.

Disponível em: http://vadebike.org/2009/02/cycle-chic/ Acesso 28 ago 2011).
}

Dessa maneira, interpretados por processos de designação que apagam o sujeito em detrimento do objeto: "A bicicleta é democrática e inclusiva"; segregados pelos processos de universalização que ao mesmo tempo os exclui do direito à cidade e faz opaca essa exclusão ("a bicicleta é para todos; é coisa de gente"), os ciclistas são chamados a ocupar o seu lugar nos processos de identificação/subjetivação que constituem os sujeitos urbanos a partir de um discurso sobre a mobilidade urbana sustentável e democrática, no qual sedimentam-se e naturalizam-se esses efeitos de sentido, legitimados e perpetuados no ordinário do sentido pelo funcionamento da mídia e da lei.

\section{A CIDADE SE MEXE}

No início de nosso trabalho colocamos como objetivo deslocar os sentidos do discurso da "violência na cidade" para os de convivialidade urbana e os sentidos de "caos no trânsito" para a análise dos discursos sobre "mobilidade urbana". Este deslocamento foi possível por considerar a cidade como "uma das formas do homem, definido não como 'espécie' mas como ser histórico e simbólico, produzir sua vida na convivialidade" (Orlandi, 2004: $65)$.

Desta maneira, a "violência no trânsito" deixa de ser analisada como um subproduto natural da cidade, como afirmam discursos que naturalizam a violência como efeito necessário do fenômeno urbano, apagando suas causas sociais e políticas; ou como uma consequência necessária da "cultura brasileira regida pela lei do mais forte". Ao contrário, do ponto de vista discursivo, podemos considerar, com base em Orlandi (2004:65) que: 
a violência é uma metaforização mal sucedida da quantidade, essa sim constitutiva em primeira instância do que é o urbano, da cidade. O deslizamento do conflito - este também constitutivo para a violência já é igualmente um trabalho da história, da sociedade, da ideologia.

Para a autora a quantidade é uma propriedade constitutiva do funcionamento simbólico da cidade nas atuais condições de produção. A quantidade é constitutiva dos processos de significação da cidade e da cidadania: a cidade supõe muitos, heterogêneos, no mesmo lugar. No caso que analisamos, a quantidade de carros, motos, pedestres e bicicletas nas mesmas vias de circulação produzem conflitos mal resolvidos pelas falhas do Estado em ocupar seu lugar e pelas múltiplas formas de se subjetivar no espaço urbano que fogem ao enquadramento do discurso jurídico-administrativo que encarna os sentidos da organização urbanística da cidade. Também vimos como a quantidade também está na base de processos de subjetivação na diferença, onde a predominância de bicicletas sobre outros meios de transporte urbano interfere na ordem das relações sociais e interpessoais, produzindo uma verticalização diferenciada das relações de dominância: "o ciclista sempre tem a razão na cidade das bicicletas". Assim, pelo excesso ou pela falta, a bicicleta é significada a partir dos processos de metaforização da quantidade em relação à constituição das identidades dos sujeitos urbanos.

Como afirma Orlandi (2010), o real da cidade des-organiza o olhar totalizador do discurso urbanístico e do discurso jurídico sobre o espaço urbano.

Jogo caleidoscópico que vive o sujeito em seu corpo urbano: as relações não são de conteúdo, não são divisões, são prismáticas, movimentos que envolvem a relação espaço-tempo em múltiplas e distintas formas. Não penso fragmentos, mas "prismas" diferentes convivendo em quantidade concentrada em um mesmo espaço simbólico. (Orlandi, 2001: 8)

Com nosso trabalho queremos destacar outra propriedade que na nossa opinião é também constitutiva da cidade na sua configuração atual na formação social capitalista: o movimento. Com efeito, a circulação de mão de obra e mercadoria está na base dos processos de constituição do capital e da mais-valia. Dinheiro, mercadoria e pessoas circulam na sociedade capitalista contemporânea no frenesi das conexões virtuais globais em tempo real. Fluxo e acumulação são as duas faces paradoxais do mesmo processo que constrói o capital. A cidade contemporânea, sendo fruto das relações atuais de dominação capitalista e sobredeterminação econômica das relações sociais, se significa e constitui nessa pulsão ao movimento. É no movimento pelas vias da cidade, atravessando os espaços públicos, que os sujeitos se encontram em estado de contiguidade forçada. Nessas condições são produzidos os sentidos para a convivialidade urbana. Na contradição das relações de força desiguais, na divisão política dos direitos e deveres, nas práticas materiais e heterogêneas que significam a cidadania. Não há cidade sem quantidade em movimento, como nos permite compreender a citação de Orlandi (2001:8), quando afirma que as relações entre sujeitos no corpo urbano são "movimentos que envolvem a relação espaço-tempo em múltiplas e distintas formas".

Exploramos algumas dessas formas neste nosso trabalho, analisando os efeitos de um discurso homogeneizador sobre "mobilidade urbana". Outras formas foram perscrutadas por Soares Melo no seu trabalho sobre "a cidade das bicicletas". Porém, as várias formas materiais em que o movimento significa o corpo urbano não se esgotam nestes trabalhos. 
Novas perspectivas ficam lançadas, como as que nos apresenta o trabalho de Lucca (2010) sobre os "motoboys". E tantas outras, que nos convidam a continuar em movimento. Pois, como já diziam Fuchs \& Pêcheux (1975), a análise discursiva é um movimento em espiral, cujo fim é sempre provisório.

\section{$\overline{\text { REFERÊNCIAS BIBLIOGRÁFICAS }}$}

FUCHS, C. \& M. PÊCHEUX. (1990). A propósito da Análise Automática do Discurso: Atualização e Perspectivas. Trad. Péricles Cunha. 1 ed:1975. In: F. Gadet \& T. Hak (orgs.) Por uma Análise Automática do Discurso. Uma Introdução à Obra de Michel Pêcheux. Campinas, Editora da UNICAMP.

HAROCHE, Claudine. (1992). Fazer Dizer, Querer Dizer. Trad. Eni P. de Orlandi. 1 ed.1984. São Paulo, Hucitec.

LUCCA, Julia Frascarelli. O Sentido de Motoboy Transgressor. Língua, Literatura e Ensino. Campinas: UNICAMP, v. 5. p. 173-180 out. 2010. Disponível em: <http://www.iel.unicamp.br/revista/index.php/ lle/article/viewFile/1159/937>. Acesso em: 10 maio 2011

MARIANI, Bethânia S.C. (2001). Questões sobre a solidariedade. Em: Orlandi, Eni (org.) Cidade Atravessada. Campinas, Pontes.

MORELLO, Rosângela. (2003). Definir e Linkar: em que Sentido? In: Eni P. Orlandi. (Org.). Para uma Enciclopédia da Cidade. Campinas: Pontes/Labeurb-Unicamp, v. 1, p. 121-132

ORLANDI, Eni P. de. (1992). As formas do Silêncio. No movimento dos Sentidos. Campinas, Editora da UNICAMP.

. (2004). Cidade dos sentidos. Campinas, Pontes.

. (2009).Terrorismo: uma difícil tarefa de definição. In: Resende, Letícia M. et alii. Léxico e gramática: dos sentidos à construção da significação. Série Trilhas Linguísticas, n. 16, São Paulo: Cultura Acadêmica.

ORLANDI, Eni P. de (org). (2001). Cidade atravessada. Os sentidos públicos no espaço urbano. Campinas, Pontes.

. (2003). Para uma enciclopédia da cidade. Campinas, Pontes.

. (2010). Discurso e Políticas Públicas Urbanas. A fabricação do consenso. Campinas, RG Editora.

SOARES MELO, Edna A. (2007). A bicicleta no espaço pública da cidade: um fato de linguagem. In: N. Zattar \& O. Maluf Fronteiras discursivas. Espaços de significação entre a Linguagem a História. Campinas: Pontes, p.39-50

PÊCHEUX, Michel. (1990). Análise Automática do Discurso. 1"ed. 1969.Trad. Eni P. de Orlandi. Em: F. Gadet \& T. Hak (orgs) Por uma Análise Automática do Discurso. Uma Introdução à Obra de Michel Pêcheux. Campinas, Editora da UNICAMP. . (1988). Semântica e Discurso. Uma Crítica à Afirmação do Óbvio. 1“ ed. 1975. Trad. Eni P. de Orlandi et alii. Campinas, Editora da UNICAMP.

. (1990). O discurso: Estrutura ou Acontecimento. 1ªd. 1983a Trad: Eni P. de Orlandi. Campinas: Pontes.

. (1991). Delimitações, Inversões, Deslocamentos. 1ª ed. 1982a.Trad. José H. Nunes. In: Cadernos de Estudos Linguíísticos 19, p. 7-24. Campinas, IEL/UNICAMP.

${ }^{9}$ Cf. LUCCA, Julia Frascarelli. O Sentido de Motoboy Transgressor. Língua, Literatura e Ensino. Campinas: UNICAMP, v. 5. p. 173-180 out. 2010. Disponível em: <http://www.iel.unicamp.br/revista/index.php/ 1le/article/viewFile/1159/937>. Acesso em: 10 maio 2011. 
ZOPPI-FONTANA, Mónica. (1998). Cidade e discurso: paradoxos do real, do imaginário, do virtual. In: RUARevista do Núcleo de Desenvolvimento da Criatividade, núm. 4, p.39-54. Campinas, NUDECRI.

. (1999a).Ordem jurídica, ordem política e a (des)ordem nas ruas. In: Discurso y Sociedad, 1,1, p. 105122. Madrid, Gedisa.

. (1999b). É o nome que faz fronteira. In: Indursky, F. (org) O Múltiplo território da Análise do Discurso. Porto Alegre, Sagra-Luzzatto, p. 202-215.

. (1999c). Um estranho no ninho: entre o jurídico e o político, o espaço público urbano. Em: RUARevista do Núcleo de Desenvolvimento da Criatividade, número especial, p. 53-65. Campinas, NUDECRI. . (2004). Nossa casa, nossa cidade, nosso jardim. As miragens do cidadão comum. In: Morello, R. Giros na cidade. Campinas, Labeurb/Unicamp. 